\title{
Fujitsu's long march
}

\section{London \& Tokyo}

Fujitsu, Japan's largest computer maker, is to bid for a majority shareholding in ICL, the only British company still manufacturing mainframe computers. News of the deal, leaked to the press two weeks ahead of the planned announcement, has sent a shockwave through the computer industry as it is seen as the most daring of a series of moves by Japanese companies determined to build global competitors to the US giant, IBM.

If successful, the bid will take Fujitsu from the number four position, in terms of global revenues, to the number two position, leapfrogging NEC of Japan and Digital Equipment Corporation of the United States. But Fujitsu and ICL's combined revenues for 1989 were still less than a quarter that of IBM.

Fujitsu is expected to bid for at least a 50 per cent holding in ICL at the end of this month. The Japanese company would gain a profitable subsiduary (ICL had pretax profits of $£ 145.7$ million last year) and easy access to the computer market in the European Communities (EC), when trading restrictions between the EC partners are abolished in 1992. Some link up between the two companies had been expected, since Fujitsu already supplies ICL with semiconductors for its machines. But few predicted that STC, ICL's parent company, would be prepared to give up a majority stake.

Fujitsu's takeover bid is just one of several moves by Japanese computer manufacturers intended to form alliances against IBM with European and US companies. European companies are not themselves seen as serious competitors; with the backing of the Ministry of International Trade and Industry (MITI), Japanese companies are concentrating single-mindedly on overtaking IBM.

Apart from its ICL link, Fujitsu has a major shareholding (43.6 per cent) and cooperative marketing agreement with the US computer maker Amdahl, which uses Fujitsu technology in its computers. The Japanese company also has an agreement with Siemens of West Germany, whereby Siemens sells Fujitsu computers with Siemens labels on them.

Hitachi and NEC have gone into similar licensing agreements and joint ventures in Europe, producing a marketing network for Japanese companies that in total matches IBM's in scale.

UK Opposition Labour party technology spokesman Lewis Moonie says he is "disappointed that the only remaining British mainframe manufacturer has to pass into foreign hands". He blames the lack of a coherent government strategy for information technology for the current state of the British computer industry, and is also concerned about the takeover of the UK software company Hoskyns by the French group Cap Gemini Sogeti, announced last week.

But Martin Campbell-Kelly, who lectures in the history of the computer industry at the University of Warwick, does not view the ICL takeover as the death knell for the British computer industry. Rather, he says, the industry has moved on from the manufacture of hardware to the production of integrated computer systems assembled from hardware manufactured elsewhere.

Campbell-Kelly says that two important questions surrounding the ICL deal remain unanswered. The first is whether Fujitsu will discontinue ICL's mainframe range to concentrate on marketing their own products. The second is what will happen to ICL's research and development base once the company passes into Japanese hands.

Some UK observers predict a diminution of research, but Japanese electronic companies typically re-direct large percentages of their profits into research and development, suggesting that Fujitsu will make full use of ICL's research capabilities. Several Japanese computer manufacturers have already set up research units in Europe and the United States.

Peter Aldhous \& David Swinbanks

\section{Japan dreams deep dreams}

\section{Tokyo}

JAPAN's ambitions to have the biggest and the best of everything appear to have touched the Ocean Development Division of the Science and Technology Agency, which last week sent in a request for funds to begin work on the design of the world's largest ocean drilling ship.

The initial request is for just $¥ 97$ million $(\$ 620,000)$. But the design is to be for a ship of 18,000 tons (gross) - more than twice the size of the US ship JOIDES Resolution which is used in the International Ocean Drilling Program. Yoshiro Miki, director of the Ocean Development Division, says the ship would be equipped with all the most sophisticated Japanese instruments, would cost about $¥ 30,000-¥ 40,000$ million ( $\$ 200-\$ 270$ million) and would be ready before the end of the decade.

The International Ocean Drilling Program is scheduled to end in 1993. But it may be extended by another five years or so, in which case the Science and Technology Agency will discuss how to share the drilling activities of the two ships with the countries involved in the programme.

Somewhat surprisingly, the Ministry of Education, Science and Culture, which at present supports Japan's participation in International Ocean Drilling Program, has not expressed any opposition to the Science and Technology Agency's plans. The two organizations often fight for territory in basic research but Miki says ocean research is one area in which they have learned to collaborate.

The only thing that might thwart the agency plans to build the drilling ship is the Science and Technology Agency's commitments to space research. The agency's participation in the US space station project will drain its resources over the next decade. But Miki and other agency officials are determined to try to maintain a well-balanced budget for all areas of scientific research.

The Ocean Development Division has other new projects, besides the drilling ship, which it hopes to cover with a total 24 per cent increase in its budget for next year. The budget request, for $¥ 12,000$ million ( $\$ 80$ million), will almost certainly be whittled down by the Ministry of Finance over the coming weeks but is in line with recommendations published by the Council for Ocean Development of the Prime Minister's Office in May and a call for increased research on Earth science and technology issued last month by Japan's highest science policy-making body, the Council for Science and Technology. Miki says he is confident that the new projects will be funded.

Biggest among them is the DEEP STAR (Deep-sea Environmental Exploration Program-Science and Technology for Advanced Research) project, which aims at growing deep-sea microorganisms in the laboratory at pressures up to 650 atmospheres (the pressure at a depth of about 6,500 metres in the ocean). The project began this financial year with a budget of $¥ 790$ million ( $\$ 5.2$ million) to build equipment for collecting microorganisms from the sea floor. A total investment of about $¥ 4,500$ million ( $\$ 30$ million) will be required over three years to complete facilities on land, Miki says.

Koki Horikoshi of the Institute of Physical and Chemical Research (RIKEN), who won international recognition for his 'Superbug' project (see Nature 310, 172; 1984), will head the DEEP STAR project at the Japan Marine Science and Technology Center (JAMSTEC).

The budget request also includes several hundred million yen to study ocean circulation and climate change near the North Pole in collaboration with the United States and West Germany.

David Swinbanks 